\title{
RESEARCH
}

Open Access

\section{GPS tracking data reveals daily spatio- temporal movement patterns of waterfowl}

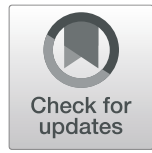

Fiona McDuie ${ }^{1,2^{*}}$ D, Michael L. Casazza ${ }^{2}$, Cory T. Overton², Mark P. Herzog ${ }^{2}$, C. Alexander Hartman², Sarah H. Peterson ${ }^{2}$, Cliff L. Feldheim ${ }^{3}$ and Joshua T. Ackerman ${ }^{2}$

\begin{abstract}
Background: Spatio-temporal patterns of movement can characterize relationships between organisms and their surroundings, and address gaps in our understanding of species ecology, activity budgets, bioenergetics, and habitat resource management. Highly mobile waterfowl, which can exploit resources over large spatial extents, are excellent models to understand relationships between movements and resource usage, landscape interactions and specific habitat needs.
\end{abstract}

Methods: We tracked 3 species of dabbling ducks with GPS-GSM transmitters in 2015-17 to examine fine-scale movement patterns over $24 \mathrm{~h}$ periods (30 min interval), dividing movement pathways into temporally continuous segments and spatially contiguous patches. We quantified distances moved, area used and time allocated across the day, using linear and generalized linear mixed models. We investigated behavior through relationships between these variables.

Results: Movements and space-use were small, and varied by species, sex and season. Gadwall (Mareca strepera) generally moved least (FFDs: $0.5-0.7 \mathrm{~km}$ ), but their larger foraging patches resulted from longer within-area movements. Pintails (Anas acuta) moved most, were more likely to conduct flights $>300 \mathrm{~m}$, had FFDs of 0.8-1.1 km, used more segments and patches per day that they revisited more frequently, resulting in the longest daily total movements. Females and males differed only during the post-hunt season when females moved more. $23.6 \%$ of track segments were short duration (1-2 locations), approximately 1/3 more than would be expected if they occurred randomly, and were more dispersed in the landscape than longer segments. Distance moved in 30 min shortened as segment duration increased, likely reflecting phases of non-movement captured within segments.

Conclusions: Pacific Flyway ducks spend the majority of time using smaller foraging and resting areas than expected or previously reported, implying that foraging areas may be highly localized, and nutrients obtainable from smaller areas. Additionally, movement reductions over time demonstrates behavioral adjustments that represent divergent energetic demands, the detection of which is a key advantage of higher frequency data. Ducks likely use less energy for movement than currently predicted and management, including distribution and configuration of essential habitat, may require reconsideration. Our study illustrates how fine-scale movement data from tracking help understand and inform various other fields of research.

Keywords: Activity budgets, Animal movement, Contagion index, Energetics, Fine-scale movement, High frequency GPS, Movement ecology

\footnotetext{
* Correspondence: fiona.mcduie@sjsu.edu

'San Jose State University Research Foundation, Moss Landing Marine

Laboratories, 8272 Moss Landing Rd, Moss Landing, CA 95039, USA

${ }^{2}$ U.S. Geological Survey, Western Ecological Research Center, Dixon Field

Station, 800 Business Park Drive, Suite D, Dixon, CA 95620, USA

Full list of author information is available at the end of the article
}

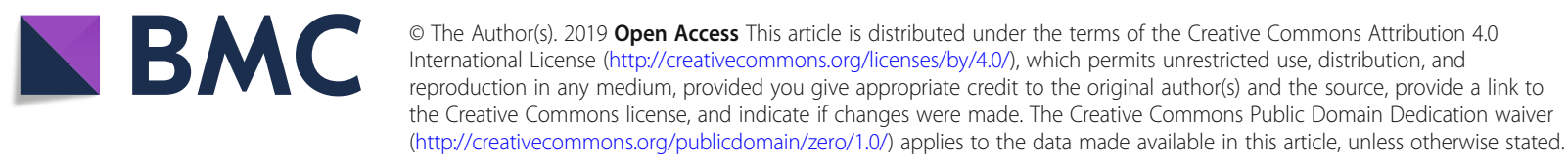




\section{Background}

Animals adjust foraging activity, and therefore movement distances, in relation to available resources [1-3]. Consequently, how they interact with their environments reflects their ecological constraints, habitat or resource requirements and landscape heterogeneity [4]. The scale of animal movements can identify and characterize the environmental or behavioral processes which drive any given movement pattern, as well as represent the energy costs associated with various behaviors or activities. Characterizing movement patterns allows us to better inform and develop theories in related fields of research, such as optimal foraging theory, bioenergetics and estimate time or activity budgets that are directly shaped by movement behavior and distribution of resources [1, 5-7]. The size of, and duration spent in habitat patches reflects the distribution and availability of necessary or used resources for the population in question, a condition that applies across taxa $[8,9]$. Therefore, a detailed understanding of how and when animals move about and use the landscape can help develop and improve management and conservation strategies, including habitat distribution and forage quality/quantity needs or objectives.

A variety of intrinsic and extrinsic factors such as phenology, sex, species, resource availability and disturbance affect activity patterns and the need to move. Migratory species need to fatten prior to lengthy migrations and refuel upon return to wintering areas [10-12], while residents have food and habitat needs throughout the year. Hunting activity affects when and how ducks use sanctuaries and refuges, and can limit flight distances ( $[13,14]$, but see [15],), and some species, for example grey teal (Anas gracilis) [16] and mallard (A. platyrhynchos) [17], demonstrate movement variation according to the distribution of resources.

Waterfowl can rapidly move long distances, which enables access to resources over a large area. Although lengthy waterfowl movements and migrations have been studied in depth (e.g. [18-22]), limitations on the frequency of data acquisition and fine-scale movements have prevented detailed analyses of the relationship between movement patterns and behavior. For example, distances and timing of inter-patch movements varied extensively among studies (see review in [23]), often according to location, year or season and within and between species. Legagneux et al. [24] found mallard forage flight distances (FFDs) in France to vary between $0.5-1.3 \mathrm{~km}$ by year, while a study by Bengtsson et al. demonstrated distances of $3-5 \mathrm{~km}$ in Sweden. In Louisiana, USA, Cox and Afton [25] found FFDs of northern pintails (A. acuta; hereafter pintail; $10.7-18.5 \mathrm{~km}$ ) that were considerably longer than FFDs of conspecifics in California which Fleskes et al. [26] found ranged from $3.3-7 \mathrm{~km}$. Discrepancies among studies may be caused by divergent methodologies and assumptions associated with limited data from low resolution and low accuracy tracking methodologies (such as radio or VHF), that have been used to carry out much of the prior research. Advances in technology such as high resolution GPS tracking, can provide the level of detail needed to identify and characterize fine-scale space-use by waterfowl and reveal critical habitat. The use of such technology is increasingly common in identifying and characterizing fine-scale movements in animal ecology [27-29]. High frequency movement data are particularly useful for revealing variation in the factors which drive movement $[30,31]$ and allow us to link movements with behaviors and gain greater insight into species and behavioral ecology [27].

The broad aim of our study was to characterize fine, spatio-temporal scales of duck movements to identify or inform movement behavior, and determine whether movements varied according to species, sex or time of year. In California's Central Valley (Fig. 1), the habitat changes considerably throughout the year according to the season, rainfall, agricultural practices and landscape management, which directly influences waterfowl distributions in the large multi-species community [32]. As movement and space-use are expected to diverge as a result of various intrinsic or extrinsic processes such as species ecology and habitat heterogeneity. Therefore, we tracked three species of North American waterfowl (gadwall (Mareca strepera), mallard and pintail) with GPS-GSM at the highest frequency possible $(30 \mathrm{~min}$ interval location data), to precisely quantify daily ('bird day'- 24h) movements, space-use and time allocation across 4 seasons (hunt: Nov-Jan; post-hunt (or spring migration): Feb-Apr; summer: May-Aug; and pre-hunt (or fall migration): Sep-Oct). We retained only data collected outside periods when sex or specific life history stages (nesting, brooding, molting and migration) are likely to substantially affect the ability/need to move or fly. We tested hypotheses that species and sexes would differ in these variables. Finally, to determine whether it is possible to use higher frequency data to identify specific bird behaviors, we investigated how time spent in an area was related to locations of, and movement between and within, individual patches.

\section{Methods}

\section{Study species and area}

We focused on tracking the movements of three dabbling duck species within California's Central Valley: mallard ( $\mathrm{n}$ female $=38, \mathrm{n}$ male $=7$ ), pintail ( $\mathrm{n}$ female $=36, \mathrm{n}$ male $=10)$, gadwall $(\mathrm{n}$ female $=18, \mathrm{n}$ male $=0$ ). Mallard and gadwall breed, and are predominantly resident, in California year round, whereas pintail, typically migrate north (March-April) to breed in Canada and Alaska [20, 33-35]. 


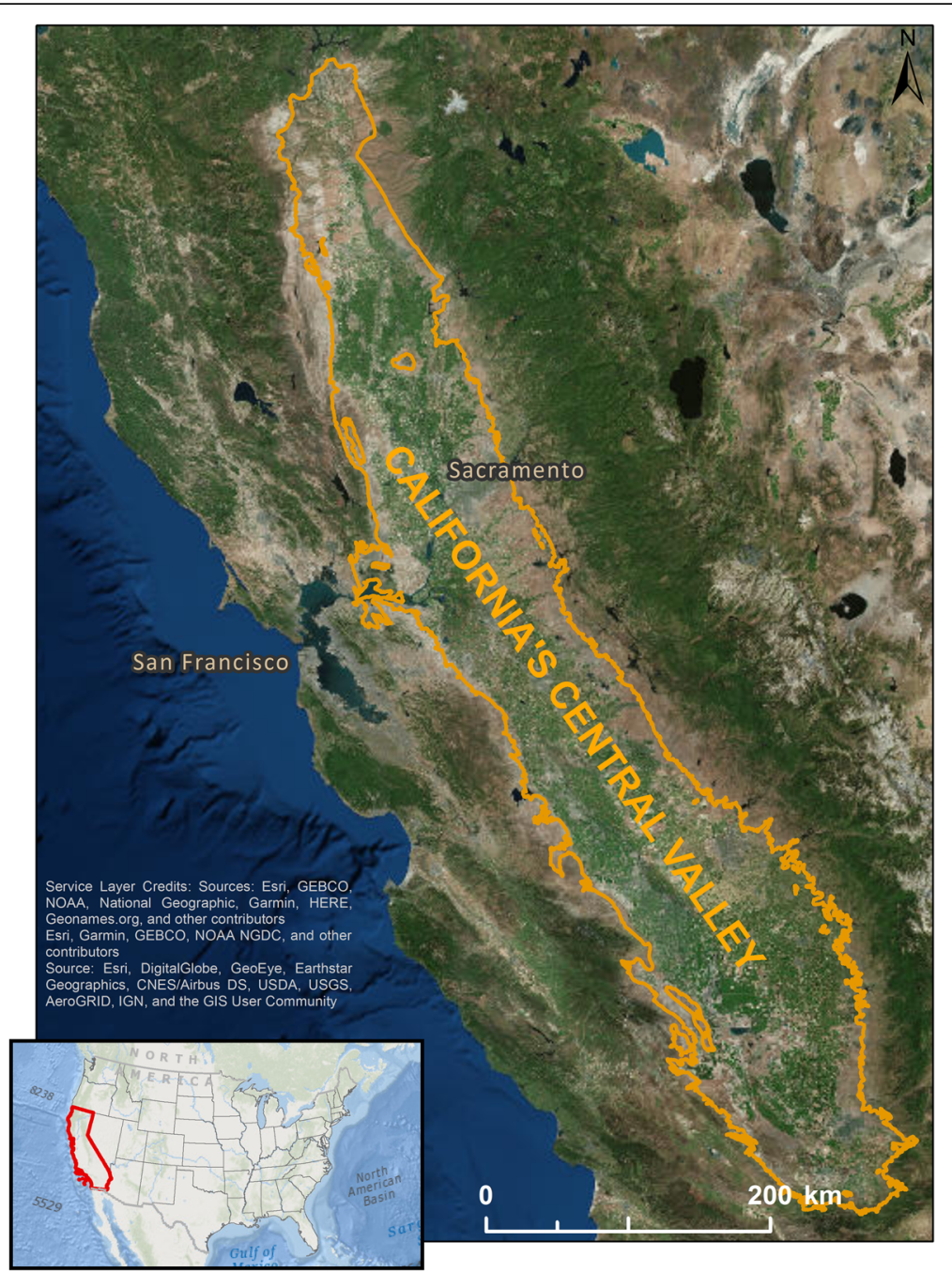

Fig. 1 Map showing California's Central Valley with California outlined on the Continental USA map inset. All 3 species of dabbling ducks (gadwall, mallard and pintail) were tracked with GPS within California producing 2481 'bird days' with complete sets of 48 locations at 30 min intervals which were used to estimate movement and space-use of each species

Their return to the Central Valley and Suisun Marsh can vary, but is generally between August and December. We captured ducks in the upland nesting fields on Grizzly Island State Wildlife Area $\left(38.13831^{\circ} \mathrm{N} 121.9781^{\circ} \mathrm{W}\right)$, on 8 private duck clubs in Suisun Marsh, and at Howard Slough State Wildlife Area in the Sacramento Valley $\left(39.46726^{\circ} \mathrm{N}, 121.8774^{\circ} \mathrm{W}\right)$.

\section{Field methods and electronic tracking}

We began collecting data on January 20th, 2015 and concluded on March 19th, 2017. We captured ducks in Suisun Marsh during 3 time periods: fall, before the hunting season (September to October); winter shortly after the hunting season (February to March); and nesting females in spring/summer (April to July), in order to acquire data throughout their annual life cycle. Additionally, a small number of pintail $(n=15)$ were captured using rocket nets at Howard Slough State Wildlife Area during spring (March to April), just prior to the northward migration. Hunting seasons vary by region but generally begin in mid-October and conclude in late January. Nesting gadwall and mallard females were found on Grizzly Island State Wildlife Area using standard nest dragging techniques [20] and typically captured with large dip nets $[36,37]$. We trapped male mallards and pintail on the private duck clubs using baited funnel traps [38] post-hunting season and during the summer (February-March and June-August respectively). Rocket nets were used to capture male and female pintail before the commencement of the hunting season in September-October [36]. Individuals 
were aged as hatch-year (HY) or after-hatch-year (AHY) based on feather and molt plumage [39] and only adult birds received GPS transmitters.

All birds were marked with individually numbered aluminum leg bands and we took morphometric measurements to assess size and weight prior to marking. Transmitter and harness attachments were typically less than $3 \%$ of body weight at the time of capture for the lightest marked group (female gadwall) and as low as $1.5 \%$ for our heaviest group (male mallards [40]). This ensured that the deployment package weight remained within acceptable body weight limits for birds (3-5\%) [40-44]. Captured birds were fit with remotely programmable and solar rechargeable Ecotone ${ }^{\bullet}$ GPS-GSM SAKER L series electronic transmitters that communicate using the cellular (GSM) network. GPS transmitters had a foam pad at the base, weighed $17 \mathrm{~g}$, and measured $58 \times$ $27 \times 18 \mathrm{~mm}$. We attached transmitters to adults with back-mounted body harnesses constructed of $5 \mathrm{~mm}$ automotive elastic which is less likely to wick moisture to down feathers. Early deployments fasten the elastic ribbon with crimps, later amended to a simple double overhand knot affixed with cyanoacrylic glue, to hold the transmitter in place. Final deployment weight was $18-18.5 \mathrm{~g}$. Total handling time was approximately 20 30 min per bird, and we released each duck at the location of capture.

Transmitters were programmed to take location fixes at $30 \mathrm{~min}$ intervals. When the battery reached a minimum critical power level the logger switched to a $6 \mathrm{~h}$ interval until it was sufficiently recharged to revert to obtaining locations at shorter intervals. Location coordinates, date, time and battery status were transmitted from the tag to Ecotone (http://telemetry.ecotone.pl) via GSM text message following every fourth location. Because ducks with transmitters may often be in areas outside the range of the cellular GSM network, data were stored on board the transmitter and transmitted when they returned to areas within range of a cell tower. Stored data were backfilled until battery power and GSM signal strength allowed upload.

\section{Identifying movement and used areas}

To ensure the most complete representation of daily movement characteristics possible, we retained only data with a full $24 \mathrm{~h}$ period of consecutive position fixes at 30 min intervals. We also omitted the first two weeks of data after marking when movement may be affected by an adjustment period [45-47]. To assess our data according to factors that may influence duck movement and space-use each location was classified with the individual bird identifier (Bird ID), species, sex and which season it occurred in (hunt: Nov-Jan; post-hunt: Feb-Apr; summer: May-Aug and pre-hunt: Sep-Oct).
We established day length using sunrise and sunset times classified with the 'suncalc' package in $\mathrm{R}[48,49]$ and categorized all positions as 'day' or 'night' based upon sunset and sunrise times. Duck movement patterns vary throughout the day $[14,21]$ with the longest movement distances between forage and roost sites generally expected around sunrise and sunset (dawn and dusk) [21]. As animals are driven by circadian rhythms with movement patterns and behaviors related directly to the rise and set of the sun $[14,50,51]$, many previous studies that assess time/activity budgets and finer-scale movement distances do so for $24 \mathrm{~h}$ periods [17, 21, 26]. Additionally, waterfowl energetics models, such as 'SWAMP', use a daily time step to generate model iterations, and require data that are relevant to that sampling unit - a 'bird day' [7]. Therefore, we split movement pathways at sunrise to produce separate $24 \mathrm{~h}$ periods (i.e. 'bird days'). Within any given bird day, the ducks may spend all their time in a single area or they may transition between two or more areas, and we wanted to identify the number and size of these areas, as well as the length of time the birds spent in each. By splitting the 'bird day' at the time when the ducks were engaged in conducting longer, forage-roost flights, we increased our likelihood of incorporating all GPS positions that would potentially constitute one of these used areas (for description see next sections). Assessing duck movements using a sunrise to sunrise sampling unit also allowed us to incorporate a common circadian trigger the start of the photoperiod [52, 53], and to identify locations as 'day' (sunrise to sunset) or 'night' (sunset to sunrise), and adjust for seasonal changes in sunrise. It also satisfied our primary objective - to comprehensively evaluate movements within the $24 \mathrm{~h}$ 'bird day'. To assess temporal variation in the occurrence of longer movements, and confirm if they were more likely to occur around sunrise or sunset, we also classified 'crepuscular' periods - 'dawn' - the period from $1 \frac{1 / 2}{2}$ hours before sunrise to $1 / 2$ hour after and 'dusk' - the period beginning $1 / 2$ before sunset to $1 \frac{1 / 2}{2}$ hours after; (both encompassing astrological twilight).

We were primarily interested in areas selected and used by the birds and not transit relocations while they were flying. We identified flying behavior through assessment of the speed of the bird between each relocation. When the speed was $>10 \mathrm{~km} \mathrm{~h}^{-1}$ coming into, and going out of, any given GPS location, it indicated the bird was flying in the moment when the GPS acquired that location (and thus not selecting the habitat over which it was flying), so these were removed. This speed was selected as it is greater than duck walking/swimming (1.8-2.52 $\left.\mathrm{kmh}^{-1}\right)$ speeds [54-56] and lower than flight speeds $[57,58]$ and was identified using the 'adehabitatLT package $[59,60$ ] in $\mathrm{R}$ version 3.3.1 [49]. .By 
identifying flight in this way we could measure the distance traveled from one used habitat to the subsequent used habitat (between segment movements) and include all movements likely to represent foraging or roosting behaviors. We retained for analysis only days that included complete or nearly complete sets of positions at 30 min intervals ([46-49] positions).

In addition, inherently different life history stages present in a duck's annual cycle can directly influence behavior and movement, and are likely to be sex-specific, so we further filtered our data set to remove those periods when ducks were migrating, molting, nesting and brooding. Migration movements are long directed movements of spatial relocation. In California's Central Valley, distances of $200 \mathrm{~km}$ exceed inter-basin distances and, when achieved across 2 or more hours, and in a generally northerly or southerly direction were identified as migratory movements [19]. Ducks undergo a 'catastrophic' molt in which they shed all their primary feathers simultaneously and become flightless for between $\sim 25-40$ days $[61,62]$. As we were primarily interested in analyzing movement when flight is possible, molt periods for all individuals were identified through First Passage Time analyses $[49,63]$ of telemetry data and removed. We verified nesting behavior, nest success and the beginning of brooding following a successful hatch with weekly nest checks and through visual assessment of hen movements with telemetry data. We concluded cessation of brooding (successfully fledged or failed brood) when a hen flew and remained away for a period of $>2 \mathrm{~h}$, or moved farther/faster than would be possible with ducklings $\left(>5 \mathrm{~km} \mathrm{~h}^{-1}\right)$. Data analysis ultimately excluded all movements during migratory, molt, nesting or brooding life history stages.

\section{Identifying track segments}

We used a distance-based path segmentation approach to separate daily relocation paths into spatiotemporally continuous used areas or "segments". First, we calculated movement distances $(\mathrm{m})$ between all successive GPS fix locations (hereafter called 'step lengths'). Then, to define ecologically, geographically and behaviorally relevant spatial scales in our data, first we assessed the size of individual management unit areas in state and federal wildlife management areas of California's Central Valley including Suisun and the Sacramento Wildlife Complex [32]. These areas are often ecologically variable with respect to the plant communities, water depth etc. so we calculated the average radius of those areas and found this to be $295.81 \mathrm{~m}$. Then, we examined the empirical distribution of the natural log of step lengths, using the density function in $\mathrm{R}$ [49], following methods by Beatty et al. [64, 65]. Break points in the data were identifiable at $250-300 \mathrm{~m}$ for each species. Therefore, we selected $300 \mathrm{~m}$ as the distance that a bird would need to move, from the initial location at the start of a segment, to be considered to have switched to a new segment. Thus, all locations for each bird day (sunrise to sunrise) were assigned to one or more temporally and spatially contiguous segments. From this we estimated median step lengths within segments, between segments (from the final location in a segment to the starting location of the subsequent segment), total distance moved within segment and the total distance moved in a bird day. To identify areas and movement patterns during periods predominately associated with feeding activity [66, 67], we evaluated the proportions of segments which occurred entirely during daylight (sunrise to sunset) or nighttime (sunset to sunrise), with the remainder that included both day and night positions designated 'crepuscular' segments.

When assessing the distribution of movements throughout the day, the number of segments containing just one or two locations appeared over-represented in our data set. We calculated the expected distribution of the number of locations in a segment given the observed number of segments per day that occurred in our dataset and assuming that a new segment occurred randomly among the 48 locations obtained during the day. We compared this expectation of the number of locations per segment with the actual observed number of locations per segment per day. An excess of short duration segments among our data could occur for two reasons. First, the methodological process of segmenting locations into sunrise-to-sunrise periods may have split longer duration segments into short ones. Alternatively, short duration segments may represent a different, non-random or correlated behavioral process (e.g. disturbance) relative to longer duration segments (e.g., foraging, roosting) that also occurs more frequently than random. We wanted to investigate whether movements into short duration segments represented measurably different spatiotemporal patterns, and therefore behavioral processes, relative to longer duration ( $>3$ locations) segments. We approached this question using two methods. First, we tested for differences in the movement process by contrasting the average distance that birds moved into short duration segments compared to the distance moved into longer duration segments. Second, we evaluated differences in the spatial arrangement (dispersion) represented by, and dependence, between short duration and long duration segments. Habitat configuration and regional ecology, such as different predator communities, and levels and type of human activity vary across different regions of California. These factors could influence levels of disturbance and consequently, 
the dispersion of locations used by ducks. Therefore, we evaluated spatial arrangement patterns separately for Suisun, the northern Sacramento Valley, and Southern Oregon North-eastern California (SONEC) regions where data were most extensive.

\section{Identifying patches}

To understand dabbling duck space use, number and size of individual areas used, total area used and when and how often birds reused the same area within a day, we formed track segments into groups of spatial positions called a 'patch' [2], using minimum convex polygons (MCPs). Patches were defined as: 1 ) all locations occurring within a segment, and 2) a grouping of segments whenever the starting locations for those segments lay within $300 \mathrm{~m}$ of each other (for example see Fig. 2). Patches, therefore, are temporally discontinuous whenever 2 or more segments were combined due to proximity (i.e. when a bird returned to an area previously used that day). To evaluate the characteristics of patches we measured the area (ha), number and total size of all patches in a 'bird day', the number of relocations (time spent) in the patch, and the proportion of patches occurring in daylight, nighttime or crepuscular periods. Overlap of patch MCPs could occur if locations were intermixed - when any portion of the patch MCP area overlapped with another but starting locations of different segments were greater than $300 \mathrm{~m}$ apart. Therefore, in order to correctly estimate the total area used across an entire day, we combined the MCP boundaries around these overlapping patches to avoid totaling the overlapping area twice.

When multiple patches were used within a day, we evaluated whether ducks spent a greater proportion of their time

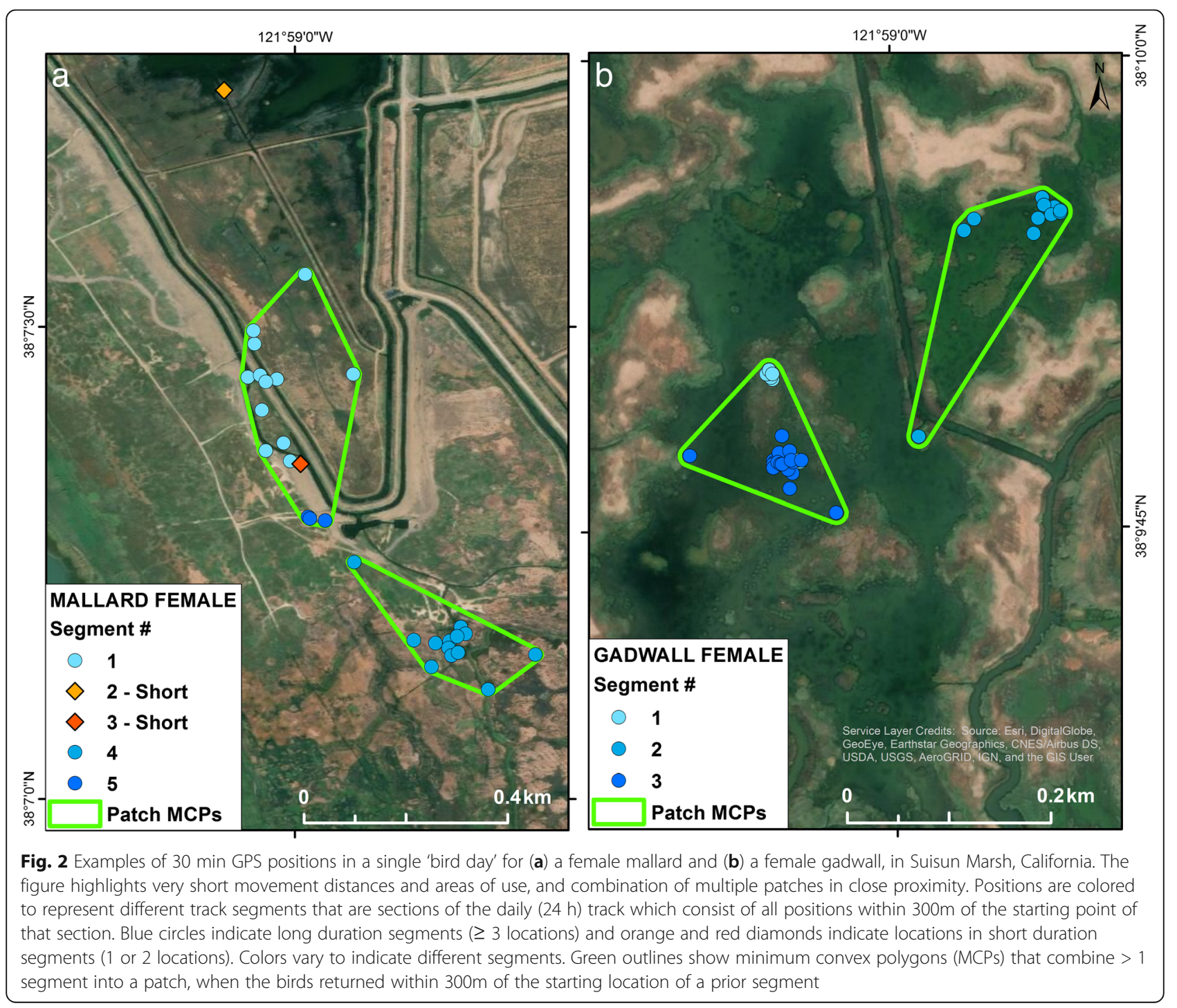


among patches that were closer/more clustered or within more remote/dispersed patches. We developed a 'spatiotemporal contagion' index (SCI) to quantify dispersion of time spent among patches by using the ratio of a time-weighted and an unweighted standard distance measure. 'Standard distance' quantifies the variance in the spatial location of a set of objects (i.e. the locations in a patch) around their mean center $[68,69]$, and a time-weighted standard distance biases the mean center toward objects with longer duration of use (i.e. patches with more locations). The ratio of these two measures provides us with an SCI that describes whether a greater proportion of the day was spent among clustered patches $($ ratio $<1$ ) or among more remotely distributed patches (ratio $>1$ ), similar to the way contagion indices quantify the spatial arrangement of habitat types in landscape ecology [70]. A value of one would indicate that time (i.e. number of locations) is equal among all patches in a bird day or that all patches were equidistant from each other.

\section{Data processing}

Relocation data were collected in the WGS84 geographic coordinate system and re-projected into UTM Zone 10 $\mathrm{N}$ projected coordinate system in $\mathrm{R}$ version 3.3.1 [49]. Data assessment and manipulation were completed in Microsoft Excel 2013 (Microsoft Corporation, Redmond, WA) and statistical analyses were conducted in $R$ version 3.3.1 [49]. All telemetry locations were buffered by $10 \mathrm{~m}$ to account for GPS error. Minimum convex polygons (MCP) were formed using base toolbox and the XToolsPro version 16.0 (๔ XTools Pro, Inc.) extension in ArcGIS for Desktop 10.3.1 [71]. Areal measurements (ha) were calculated for each buffered location or set of locations comprising a patch. As our data were non-normally distributed, all results are presented with the median with $95 \%$ confidence intervals (CI) unless otherwise noted.

\section{Autocorrelation}

We evaluated autocorrelation among our step-length data by calculating two separate autocorrelation functions (ACF) using the command 'acf' function in R [49]. The variable of interest was step length and individual bird day is the sampling unit. Two ACFs were calculated among all relocations in a given day (sunrise to sunrise period) and the average across all bird days is reported. The two ACFs were calculated from relevant sets of our data: 1) all locations for an individual within a day and, 2) all locations within a single track segment. Since path segmentation is a tool used to identify and separate non-stationary processes [72, 73], it has the natural tendency to reduce autocorrelation relative to that observed in unsegmented non-stationary data where the segments differ in mean value. That does not necessarily imply that segmented tracks are not auto correlated however, only that statistical parameters are constant within each segment, where they are not constant across all relocations. The average Pearson's coefficient for a first order autoregressive $(\mathrm{AR}(1))$ model across an entire day was 0.208 , indicating some, but non-significant (Pearson's $r$ critical value $=+/-0.28$ ) correlation among successive step lengths. As expected, splitting the tracks reduced autocorrelation among step lengths, resulting in an average AR(1) Pearson's coefficient within each track segment of -0.038 , therefore, it was not necessary to adjust for over dispersion [74].

\section{Statistical analyses}

To quantify duck movements and variation among the species and sexes for each different season we included only groups with sample sizes of at least 5 individuals and modeled a variety of metrics that estimated distances moved, area used and how time was allocated throughout the day (segments and patches; Table 1). We calculated differences in movement metrics among groups using log-transformed linear mixed models (LMER; 'Imer' function in the 'lme4' package) for most metrics. Discrete data, e.g. counts, were modelled using generalized linear mixed effect models with quasi-Poisson distributions ('glmmPQL' function in $\mathrm{R}$ package ' $M A S S$ '). Data were predominantly obtained from female ducks (84.1\%) since summer capture efforts focused on nesting hens so we were only able to model differences between pintail sexes in the hunt and post-hunt seasons and mallard sexes in summer. Since variation in movement patterns among sexes was expected, and male gadwall were not marked for this study, models quantifying differences among species included females only. Statistical comparisons were not made between seasons due to the inability to separate individual random variation from season level variation for some species/sex groups where few individuals occurred across subsequent seasons. The effective degrees of freedom for calculating test-statistics using the Satterthwaite method and significance of predictor variables within generalized linear models was assessed using Wald's Chi-square (CAR package in $\mathrm{R}$ [49]) for generalized linear models. Differences between species and sex effects are presented using pairwise comparisons across groups within each season and were adjusted for multiple comparisons using a Tukey adjustment [74]. Where pairwise comparisons among groups were quantified, we estimated the equivalent degrees of freedom for calculating test-statistics using the Satterthwaite method. Results for log-normal and quasi-Poisson distributed variables were back-transformed, where appropriate, allowing interpretation of response variables as median values with asymmetric $95 \%$ confidence limit while the differences 


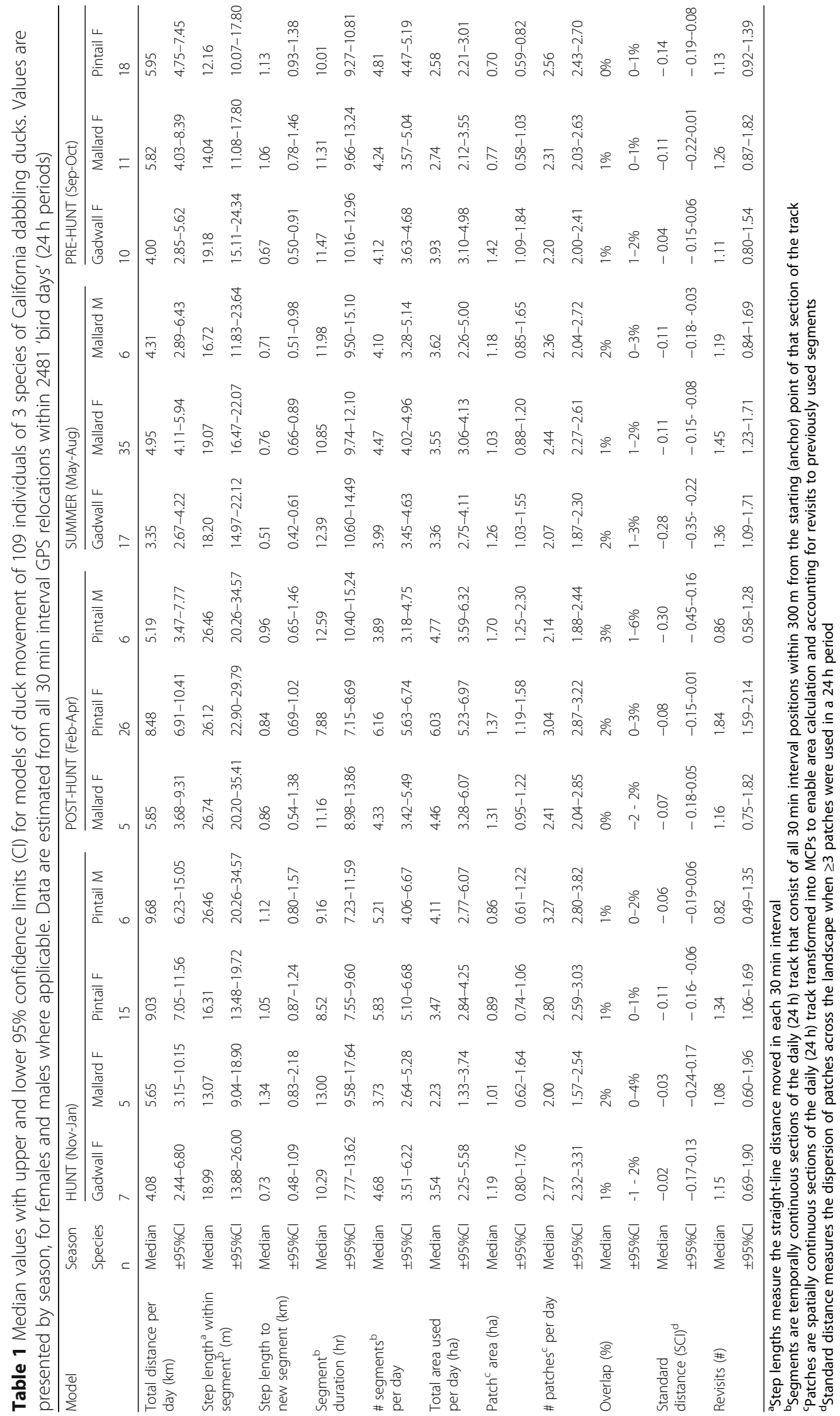


between group means were back-transformed to allow interpretation as proportional difference between groups [74].

To investigate the circadian patterns of duck movement we developed an additional model calculating the probability of longer $(>300 \mathrm{~m})$ movements occurring during dawn, day, dusk or night periods. This model used a logistic generalized linear mixed effects model (GLMER) using Laplace approximation, with a binomial response variable $(>300 \mathrm{~m}=1$ or $<300 \mathrm{~m}=0)$ and an interaction between categorical time period and group (species or sex) as fixed effect and individual as a random effect using the 'glmer' function in the 'Ime4' and 'contrasts' packages in R $[49,75]$.

Differences in the spatial arrangement of short and long duration segments could indicate different behaviors being displayed or different resources being utilized between the two types of use areas. We evaluated whether short duration segments were randomly distributed with respect to long duration segments using a Monte Carlo bootstrap simulation of one-way nearest neighbor cross-class (NN-CC) distances using the 'nncross' function in the $\mathrm{R}$ 'spatstat' package, version 1.51 [76]. We first calculated the average distance from each short duration segment to the nearest long duration segments. Then we randomly assigned locations to each class (short or long duration) while maintaining existing spatial positions and the same proportion of locations in each class. The observed NN-CC distance was compared to distribution of 10,000 bootstrapped replicates to provide a measure of the significance of our data [77]. If the distributions of short and long duration segments are spatially independent the resulting Monte-Carlo $p$-value would be near 0.5 . If short duration segments were spatially associated close to, or intermixed with, long duration segments the $p$-value would be near 0.95; and if the short-duration segment distributions were more dispersed and/or in different locations, the $p$-value would be under 0.05. A significantly more dispersed one-way Monte Carlo result could represent either a wider distribution of short duration segments or inclusion of more flying locations as the bird flies between highly clustered long duration segments. However, if the latter situation was occurring we would expect that movement into and movement out of a short duration segment would tend to be unequal, because it is unlikely that most locations would be exactly half way between longer used segments. In addition, movement into a short duration segment should, on average, be shorter than the movement into a longer duration segment if short duration segments represented flight between longer duration segments. Therefore, we tested for equal distances moved into short and long duration segments using an ANOVA in R version 3.4.3 [49].

To determine if movement changed as the time spent within a segment increased we tested the relationship between segment duration (\# of locations i.e. time spent, within the segment), and median distance moved between consecutive locations within the segment, using loglinear mixed models with species, sex, season, time of day (day vs. night) and segment duration as fixed effects and a random intercept for each individual. For this analysis, our inference is limited to the interactive relationship between segment duration and whether this effect differed between the day and the night. The statistical difference in slopes estimated by our mixed effect model was tested using a Wald Chi-square test calculated with the Anova function in the 'car' package in in R version 3.4.3 [49].

\section{Results}

We recorded 118,829 locations over 2481 bird days on 109 individuals of 3 species of waterfowl: pintail ( $43.7 \%$ of days tracked: female $=876$; male $=209)$, mallard $(31.7 \%$ of days tracked: female $=601$; male $=609)$, gadwall $(24.5 \%$ of days tracked: female $=186$; male $=0$ ), all moving within California (Central Valley Joint Venture Area - 81.0\%), SONEC (17.4\%) and adjacent areas of California outside the Central Valley (1.6\%). Data were separated and analyzed for interspecific (females only) and intersexual differences where possible, by seasons.

\section{Distance and area used \\ Hunt season}

During the hunt season gadwall moved $45 \%$ of the total distance moved by pintail across a bird day $\left(t_{25.60}=-2.812, p\right.$ $<0.05$; Table 1, Fig. 3). Mallard spent significantly more time $(153 \%)$ in segments than pintail $\left(t_{24}=2.651, p<0.05\right.$; Table 1, Fig. 3) and used $71 \%$ of the number of patches used by pintail $\left(t_{24}=-2.758, p<0.05\right)$. There were no intersexual differences in any model.

\section{Post-hunt season}

During the months of February to April, after the hunting season, mallard spent $142 \%$ of the time pintails spent in track segments $\left(t_{29}=3.069, p<0.01\right.$; Table 1 , Fig. 3) and used $70 \%$ of the number of segments used by pintail $\left(t_{29}=\right.$ $-2.878, p<0.01$; Table 1, Fig. 3). Mallard also used $80 \%$ the number of patches of $>3$ locations, compared with pintail $\left(t_{29}=-2.646, p<0.05\right.$; Table 1, Fig. 3$)$.

Pintail sexes differed during this season with females generally moving more than males. This was significant in total distance moved per day, with pintail females moving $163 \%$ of the distance that males moved $\left(t_{19.93}\right.$ $=2.264, p<0.05$; Table 1, Fig. 3$)$, they spent less time $(62 \%)$ in segments $\left(t_{30}=-4.452, p<0.001\right.$; Table 1 , Fig. 3), used $142 \%$ the number of segments that males used ( $t_{30}=4.273, p<0.001$; Table 1, Fig. 3 ), and revisited those segments $214 \%$ more frequently $\left(t_{30}=3.683, p<0.001\right.$; Table 1, Fig. 3). However, females spent more time among 

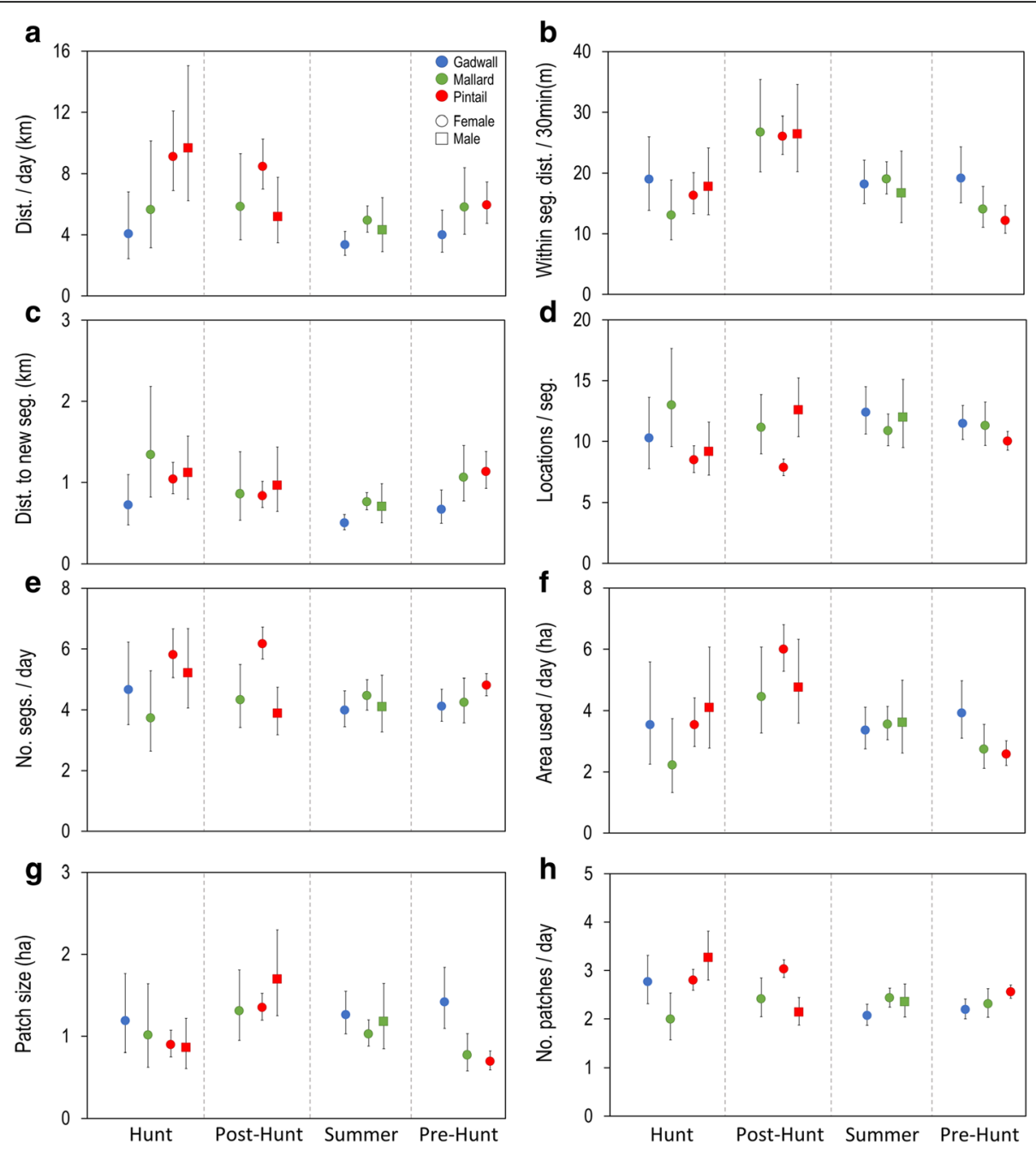

Fig. 3 Movement data from GPS tracking of gadwall, mallard and pintail of California's Central Valley separated by season (hunt: Nov-Jan; posthunt: Feb-Apr; summer: May-Aug; pre-hunt: Sep-Oct) and identified for species (gadwall: blue, mallard: green, pintail: red) and sex (female: circle; male: square) groupings: (a) total distance moved per day (24 hr period), (b) distances moved in meters per 30 min (step lengths) within track segments, (c) distances moved in kilometers per 30 min (step lengths) when switching to a new track segment, (d) segment duration (represented by the number of 30 min locations in a track segment; e.g. 10 locations $=5$ h), (e) number of track segments per day, (f) total area used per day in hectares, accounting for revisits and overlap of previously used patches, (g) size of individual patches in hectares and, (h) number of patches used per day, accounting for revisits and overlap of previously used patches

clustered patches than males (SCI; $t_{19.07}=3.024, p<0.01$; Table 1, Additional file 1: Figure S1).

\section{Summer}

Differences between non-breeding gadwall and mallard during the summer months of May through August, were limited with gadwall moving less than mallard. Their total distance moved in a day was $67 \%$ that which mallards moved and when switching to a new segment (>300 m movement), this distance was again $67 \%$ that moved by mallard $\left(t_{37.44}=-3.624, p<0.001\right.$; Table 1 , Fig. $3)$. This meant that gadwall spent more time in segments that were more clustered than mallards $\left(t_{28.93}=-\right.$ 4.27, $p<0.001$; Table 1, Additional file 2: Figure S2). In addition, gadwall used $85 \%$ of the number of patches that mallards used $\left(t_{50}=-2.435, p<0.05\right.$; Table 1 , Fig. 3$)$. There were no sex differences in mallards during summer.

\section{Pre-hunt season}

When moving within a track segment gadwall moved 158\% the distance that pintail moved in those $30 \mathrm{~min}$ intervals $\left(t_{29.36}=3.054, p<0.05\right.$; Table 1, Fig. 3$)$, but when switching to a new segment their FFDs were $59 \%$ those moved by pintail. With respect to area used, gadwall used a total area (ha) that was $152 \%$ the area used by pintail in a day $\left(t_{26.07}\right.$ $=3.043, p<0.05$; Table 1, Fig. 3), used fewer patches $(86 \%)$ than pintail and those patches were significantly larger $\left(204 \% ; t_{34.14}=3.230, p<0.01\right.$; Table 1, Fig. 3). Those 
patches were also $184 \%$ larger than patches occupied by mallard $\left(t_{22.17}=4.796, p<0.001\right.$; Table 1, Fig. 3$)$. Finally, in this season we saw the only evidence of significant differences among species or sexes in overlap of patches when gadwall patch overlap was double that of pintail $\left(t_{356.01}=3.615, p<0.01\right.$; Table 1, Fig. 3).

\section{Behaviorally influenced movement \\ Short segments}

Of the 12,055 track segments, $33 \%$ were of short duration (1-2 locations; for example see Fig. 2a). Of these, 9.4\% occurred at the beginning or end of the 'day', an artefact of our methodological constraint of splitting longer tracks into separate $24 \mathrm{~h}$ bird days at sunrise. The remaining portion of short duration segments (23.6\%) was substantially higher than would have been expected if the number of locations per segment occurred randomly during the day. Based on parameter constraints from our dataset (i.e. 48 locations/day, and the observed distribution of number of segments/day), only $17.8 \%$ of segments would consist of 1-2 locations. Therefore, short duration movements occurred 33\% more often than expected. To determine if these short duration segments represented a different kind of movement, we analyzed the distance moved into each segment duration type, which did not differ significantly (LMER: $\mathrm{F}_{1}, 9390.19=3.75, p=0.06$ ). We also analyzed the distribution patterns of each and found that the short duration segments were significantly more dispersed than long duration segments according to random bootstrapped Monte Carlo assignments ( $p<0.0001$; Fig. 4$)$.

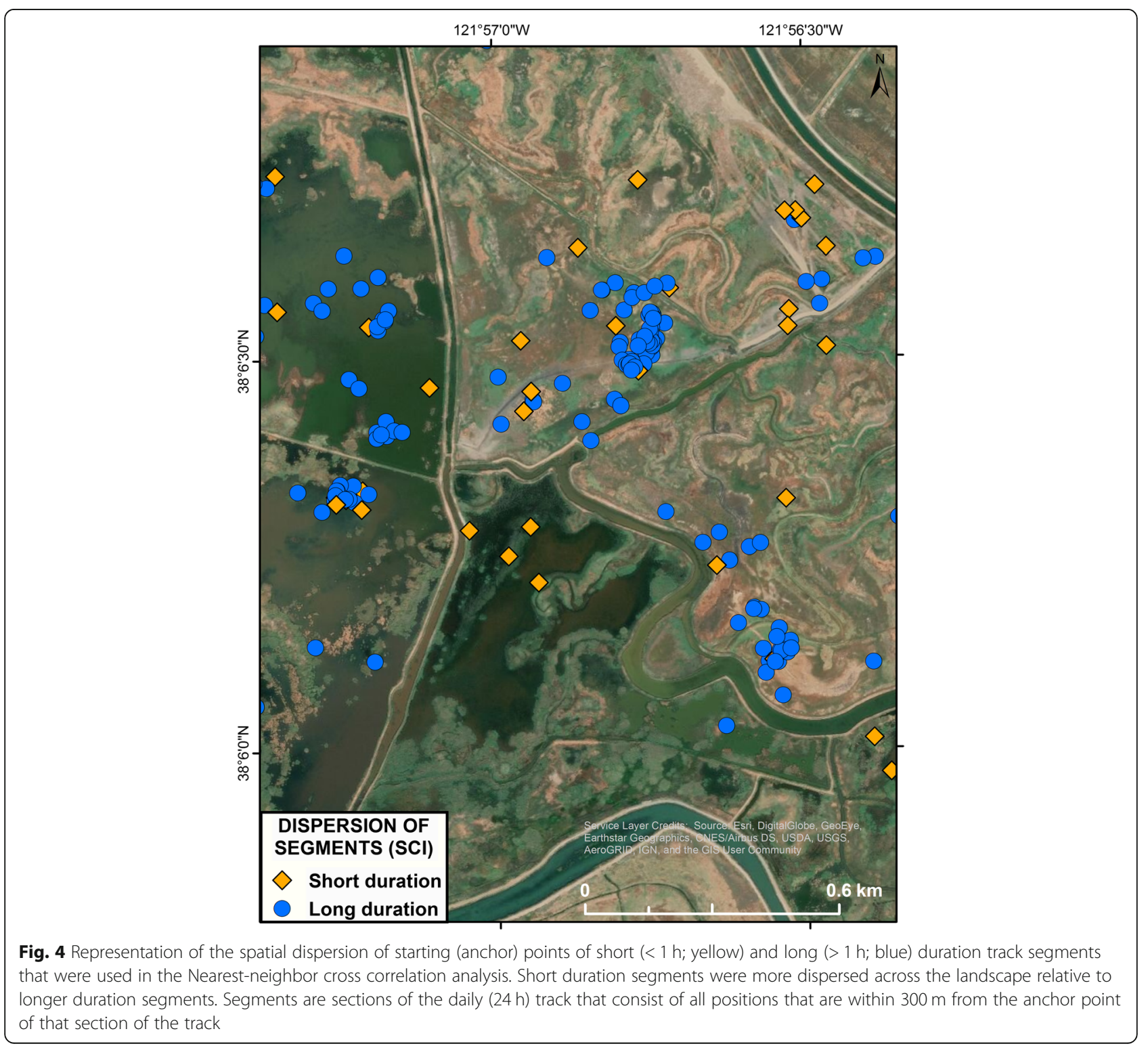




\section{Reduced movement}

Our high frequency data highlighted a tendency for ducks to reduce movement within segments as the time spent within segments increased. Step length $(\log )$ decreased the longer ducks spent in segments both during the day (Fig. 5; GLMER: $\mathrm{b}=-0.0052, \mathrm{SE}=0.0004, \mathrm{t} 106667.1=-12.803$, $p<0.001$ ) and at night (Fig. 5; GLMER: $\mathrm{b}=-0.0079$, $\mathrm{SE}=0.0006, \mathrm{t} 101970.3=-13.1133, p<0.001)$ when the decline in movement was statistically greater than during the day $($ Chi-sq $=13.089, \mathrm{df}=1 ; p<0.001)$.

\section{Time of day movement}

In general, the probability of conducting a foraging flight greater than $300 \mathrm{~m}$ was greater for all species at dawn and dusk and least during the night (Fig. 6). In the hunt and post hunt seasons there were no significant differences in the way species responded in different time periods (dawn, day, dusk, night), only overall effects that showed that mallard were $42 \%$ less likely to move $>300$ $\mathrm{m}$ during the hunt season $(\mathrm{z}=-2.855, p<0.05)$ and $56 \%$ less likely during the post-hunt $(\mathrm{z}=-4.04, p<0.001)$. During summer and the pre-hunt seasons the species responded differently at different times of day. In summer, gadwall made these longer movements $56 \%$ less often than mallard during dawn $(\mathrm{z}=-5.424, p<0.001)$ and dusk $(\mathrm{z}=-5.766, p<0.001)$, and similarly, in the

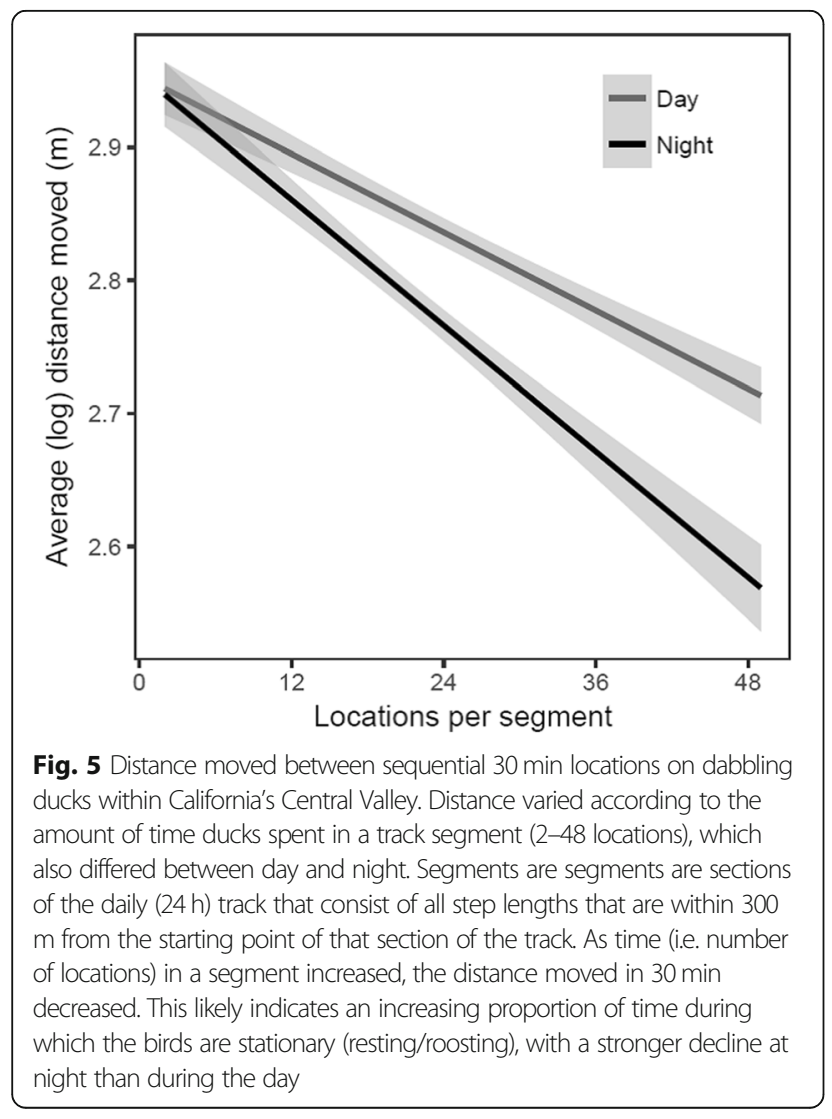

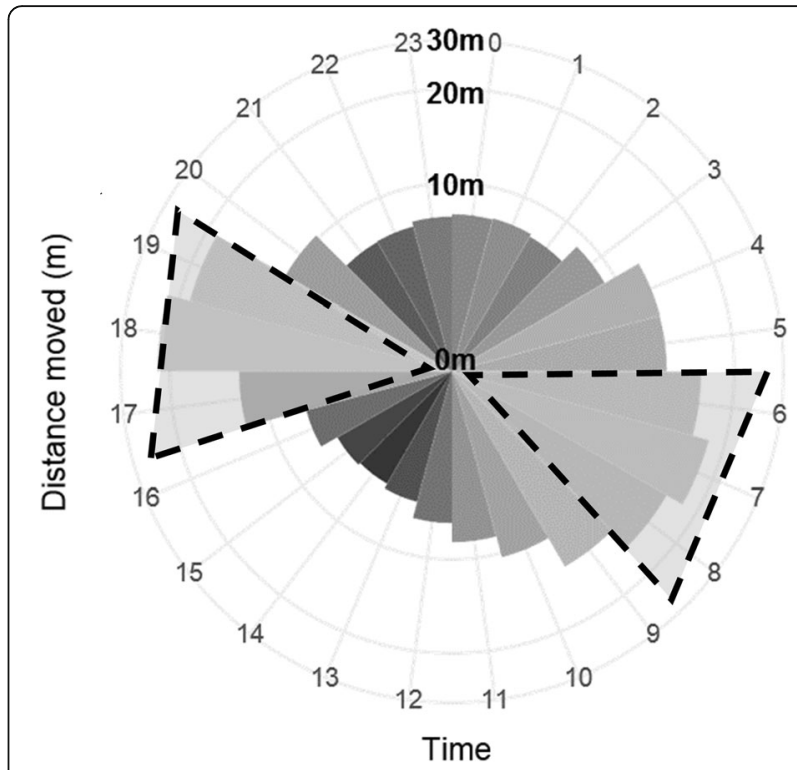

Fig. 6 Median movement distances of dabbling ducks of California's Central Valley obtained with GPS showing 30 min interval movement distances by hour of the day. Data from the entire duration of the study show longer movements were typically made in the hours around dawn (05:30 to 08:30) and dusk (16:30 to 19:30 h; grey shaded triangles with dashed outline). The grey circles represent distance in meters with the inner circle representing $0 \mathrm{~m}$ and the outer $30 \mathrm{~m}$. Grey shading varies according to distance

pre-hunt gadwall moved $>300 \mathrm{~m} 59 \%$ less often than pintail during day $(\mathrm{z}=-3.528, p<0.05)$ and $37 \%$ less across dusk $(\mathrm{z}=-5.273, p<0.001)$, and $36 \%$ less than mallard at dusk only $(\mathrm{z}=-3.877, p<0.01)$. The only evidence of inter-sexual differences was found in the post-hunt season when female pintails were 3 times more likely to move $>300 \mathrm{~m}$ than males during the day $(\mathrm{z}=7.769 .424, p<0.001)$.

\section{Discussion}

Dabbling ducks in California's Central Valley moved shorter distances and used smaller areas than expected based on previous tracking studies carried out at lower resolutions or with different methodologies (see review in $[23,26])$. Although movement varied by season, daily distances moved, were never more than $10 \mathrm{~km}$ (more commonly $\sim 3.3-6 \mathrm{~km}$ ), while inter-patch movements (or FFDs, one of the more commonly measured duck movement parameters) ranged from $0.5-2.2 \mathrm{~km}$ across species. Gadwall tended to move less than other species, with FFDs of $0.5-0.7 \mathrm{~km}$, which is shorter than the 2.5 $\mathrm{km}$ movements observed in France, in the only other study that estimated FFDs for gadwall $[13,23]$. However, when in their patches, gadwall moved more than the other species, resulting in larger spatial areas of use. This is likely related to foraging ecology as gadwall demonstrate divergent habitat selection, foraging patterns and 
behavior to target different food resources [40, 78, 79]. By contrast, pintail were generally the 'flightiest' ducks, using more segments and patches per day, which were revisited more frequently, and demonstrating a higher likelihood of conducting longer flights $(>300 \mathrm{~m})$ than the other species. This resulted in longer per day movement distances and FFDs of $0.8-1.1 \mathrm{~km}$. A study by Fleskes et al. [26], provides the only other estimates for California pintail, and notes longer FFDs of $\sim 1.7-7.1$ $\mathrm{km}$. The same study estimated mallard FFDs at $2.8-4.8$ $\mathrm{km}$ which are also longer than those we observed (0.7$1.3 \mathrm{~km}$ ). These differences may be attributable to habitat variation in the 14 years between the studies, arising from changes in habitat quality associated with enhancement strategies implemented since 1990 [32].

Although, bias from methodological differences in identification of bird locations, is likely to drive dissimilar results, our results also deviate (although to a lesser degree) from the only other GPS studies conducted on dabbling ducks. Mallards in the Netherlands and Sweden were noted to have FFDs of $0.6-2.1 \mathrm{~km}$ [17] and $<1-26 \mathrm{~km}$ respectively [21]. Inter-regional variation is known to differentially influence duck movement [16, $24]$ and our estimates of mallard space-use were also considerably less than expected from studies conducted in Europe. Our mallards used a daily area in winter of 2.2 ha $\left(0.02 \mathrm{~km}^{2}\right)$ compared with GPS estimated mallard winter daily home ranges of $9.7 \mathrm{ha}\left(0.1-30 \mathrm{~km}^{2}\right)$ in the Netherlands [17].

Movement variation by sex was most apparent during the post-hunt season when pintail females moved more than males, used a greater number of used areas that they spent less time in, and revisited more often which made them more clustered. It is the period prior to migration and after the hunting season during which the bulk of the courtship behavior occurs [66]. The pursuit of females by males may cause them to switch ponds more often in the attempt to elude males [50, 80], and this would likely explain these results. We also analyzed an additional movement metric that has not previously been described - the size of the individual patches used throughout a bird day; i.e. each patch used by ducks when not flying - between flighted relocations. The size of these foraging patches was small, approximately 0.7 (pintail females, pre-hunt) - 1.7 ha (pintail males, post-hunt; Table 1) in which ducks spent 5 and $6 \mathrm{~h}$ respectively. These infrequent movements, with ducks occupying 3.7 (mallard females, hunt season) - 6.1 (pintail females, post-hunt) track segments per day mean that our data could be augmented with lower frequency data (4-6 locations per 24h) for those species groups that currently lack high frequency information. This would substantially increase the amount of usable data across the winter months when we more commonly receive fewer data due to reduced day length and hours of sunlight that makes it more difficult for solar panels to recharge batteries.

Patterns and rates of movement influence energy expenditure [81], and this, as well as space-use, is related to the budgeting of time and activity throughout a day. These parameters are employed by energetics models such as the agent-based 'SWAMP' [7] and the spatially implicit population based model 'TRUEMET' [32]. These models are important management tools that incorporate movement metrics to understand and inform resource needs, with respect to habitat and food requirements, of ducks in the multi-species community of California's Central Valley. Until now, appropriate data on California ducks was lacking. Consequently, movement and space-use are currently overestimated for these models. Additionally, current time-activity budgets estimate the proportion of the day spent in flight, at approximately $2-6 \%[50,51,80,82]$, while our results indicate this to be approximately $0.3 \%$ on average. If flight, and the elevated energy expenditure it involves $[82,83]$, is overestimated, then estimations of energy expended by ducks is likely to be lower than is currently being modeled [82, 84-86]. .Furthermore, these metrics are currently calculated from food habits, body mass and average energy used by a caged bird [87], without empirical estimates of movement. Therefore, the costs of free-living activities, such as various forms of locomotion performed by uncaged birds, have not been included. The models also lack information that directly informs estimates of waterfowl foraging efficiency, habitat and energy requirements [7], including foraging patch selection and patch switching during bouts, while other parameters, such as forager dispersal, were judged qualitatively. Detail from the results of the present study, such as size of areas, duration of use, distances moved, revisits to previously used areas, overlap and clustering of areas, can now supply missing information and quantitatively parameterize and validate these models. We also observed some patterns, such as the relatively common occurrence of revisits to previously used areas ( $18 \%$ of days), and lengthy stays in small areas that demonstrate consistency of resource-use within a day. Currently, variables used in models are for an 'average duck', with no allowance for species-specific or behavioral variation. Combined, these results suggest that integrating species-specific data and behavioral components may further improve the accuracy of energetics models.

Duck movements included an abundance of relatively short duration (1-2 locations) movements into new and remote segments $(>300 \mathrm{~m})$ that would not be distinguishable with lower temporal resolution tracking data. These locations could be inflight points inadvertently captured when the bird is transiting between longer 
duration patches, especially if the short duration segment consists of only a single point. However, if they are followed by a return to a previously used area, or the segment includes two locations, this scenario is unlikely as the distance that must be traveled to reach these short duration segments is beyond the error of our GPS $(\sim 10$ $\mathrm{m})$. Furthermore, while dependent on life history stage, current estimates of time spent flying for ducks is approximately $6 \%$ of their day [51]. This time-activity budget seems overestimated given the short movement distances we observed. In either case, the chances of capturing inflight points are relatively small $(<3$ positions at $30 \mathrm{~min}$ intervals). They may represent a brief foray to investigate alternative foraging sites or a purposeful targeting of those areas for a particular or specialized activity; for example, if these patches represent a habitat that provides a limited and rapidly exhausted resource (Fig. 4). Alternatively, it could reflect temporary relocations to sub-optimal habitat, caused by some kind of disturbance, to which ducks are known to be susceptible, and which causes them to flush from a high quality foraging patch $[14,88,89]$. If this is the case, the spatial and temporal scale of these short segments is considerably less than estimates presented in previous work [90], further underlining the small scale at which these waterfowl interact with the landscape. It is not currently possible to disentangle the trigger of these short duration segments. However, because short flights have increased energetic demands due to the greater cost of take-offs, landings, ascents and descents [83], there are obvious implications for energetics estimations.

Resource selection theory states that when resources are plentiful animals will move less [91-93]. Therefore, where movements are small or infrequent, habitats should be profitable. Movement can be restricted for other reasons such as habitat fragmentation or loss [94, 95], although this can cause movement to increase rather than decrease [96]. However, not only did our ducks demonstrate consistently small movements in general, but they spent more time in clustered areas and reduced movement the longer they spent within an area. These aspects of movement and space-use and surprisingly small-scale habitat exploitation by these ducks suggest that the area of land needed to satisfy this population on a daily basis is considerably smaller than previously thought [26], and that these species spend time in areas where they can reach all necessary resources with relative ease. This implies that either their movements are constrained by habitat limitations and/or that food is not limiting. It is possible that the opposite is true and they are starving and unable or unwilling to move more. However, it is unlikely that food resources in the Central Valley could be so low as to restrict movement. Firstly, agricultural practices of flooding instead of burning rice fields, have increased winter food availability in this system [32]. Secondly, and probably as a result, the body condition of these populations has improved over recent decades. Pacific Flyway ducks are approximately 10\% heavier than they were in the 1980's [97] and have greater average body masses than other North American [98-102] or global [103-107] duck populations. In addition, even though pintail are known to lose mass across the winter months (from November to late January $[97,108])$, and mallard and gadwall across the summer breeding season [102, 104], their late season weights (USGS, unpub. data) are still largely greater than those of conspecifics in other regions. Therefore, our data provide no clear evidence that food resources are limiting for waterfowl in the Central Valley but rather, that our tracked ducks are able to satisfy their daily energy needs in comparatively small spatial extents.

If food is not limiting, it may be more important for management efforts to focus on developing other limited essential habitats. 'Waterfowl friendly' agricultural management programs have increased wetland and food resources [32], while other habitats, particularly "off-season" habitats such as molting wetlands, upland nesting habitat and brood ponds, are not in plentiful supply [20,26, 109]. The small movements consistently demonstrated by our ducks across seasons and species suggest a mosaic of habitats in close proximity, which meet life history requirements, is critical. Breeding ducks are limited in the distance they can move away from the nest to forage, or when escorting their broods to suitable ponds, and post-breeders are forced to leave the Central Valley to molt $[20,61]$. This not only presents a seasonal aspect to management for consideration, but wetland managers could also carefully assess the type, distribution and configuration of available habitat. For example, for the resident breeding species (mallard and gadwall), importance could be placed on increasing availability of currently insufficient nesting and brood habitat, and ensuring brood ponds exist in near enough proximity to the nesting habitat throughout the breeding period. Improving availability of appropriate molting habitat would also benefit the resident species that currently perform molt migrations to SONEC during June to September. Finally, during the hunting season, it may be more beneficial to California's waterfowl community, to have more small areas of resources than is currently thought, and their proximity to refuges could also be considered $[13,110,111]$. This enormous winter waterfowl population also inhabits the region during fall (Aug-Oct) and spring (Feb-Apr), when a plentiful food supply for post-migration refueling, and pre-migratory fattening are essential $[11,12,112]$. Consequently, natural resource management should reevaluate the juxtaposition of sanctuary, roosting, breeding and feeding areas, minimize inter-habitat distances and, most importantly, emphasize augmenting areas across the 
landscape to provide critical habitats that are currently lacking.

\section{Conclusion}

Our study's fine-scale tracking data demonstrate the strikingly small space used by these ducks and provide the most accurate and detailed information obtained to date on these species. That these estimates differ by species compared with those obtained from previous, lower frequency tracking studies, generates revised expectations for life history traits or strategies, movement patterns and behavior and related estimations used in other areas of research. Moreover, by having obtained better information on movement trajectories with higher frequency data, and identified previously undetected movement patterns likely related to specific behaviors, we can begin to develop an understanding of the factors that drive various movements, and how they vary over multiple spatio-temporal scales. Ultimately, accurate assessments of movement are essential to wildlife ecology, helping us to best understand the relationship and interaction between an animal and its environment, the effects of each upon the other $[113,114]$ and how this influences natural resource management planning and decision-making.

\section{Additional files}

Additional file 1: Figure S1. Probability density function and spatial scales based on natural log transformed step lengths for three species of California ducks tracked by GPS between 2015 and 2017. Labels on the $x$ axis have been back-transformed to display units in meters, following methods by Beatty et al. 2014 and 2015 [64, 65]. The vertical dashed line represents the break in density $(300 \mathrm{~m})$ that we used to categorize movements within and between segments. (PNG $29 \mathrm{~kb}$ )

Additional file 2: Figure S2. Conceptual model of a spatiotemporal contagion index (SCI) used to quantify the distribution of time spent among patches used in day. SCl is based on the 'standard distance' metric which quantifies the variance in the spatial location of a set of objects around their mean center. It is calculated by the ratio of the standard distance estimated among all patches without weighting (black dot and dotted circle) and the standard distance calculated when weighting the variance proportional to the amount of time spent in a given patch (grey dot and dotted circle). The dotted circles indicate the variance around the mean centers-the standard distance. When more time is spent in clustered patches (a) the $\mathrm{SCl}$ will be $<1$; when more time is spent in remotely dispersed patches the $\mathrm{SCl}$ will be $>1$ and if time is equally distributed the SCI will equal 1. (PNG $162 \mathrm{~kb}$ )

\section{Abbreviations}

ACF : Autocorrelation functions; AHY : After-hatch-year; ASY: After second year; $\mathrm{Cl}$ : Confidence intervals; FFD: Forage flight distance;

GLMER: Generalized linear mixed effects model; HY : Hatch-year; LMER: Linear mixed effects model; MCP: Minimum convex polygon; NN-CC: Nearest neighbor cross-class; SCI : Spatiotemporal contagion' index; SONEC

: Southern Oregon North-eastern California; SY : Second year

\section{Acknowledgements}

We wish to thank the following for contributions to the completion of this research: Suisun Resources Conservation District (SRCD), California Waterfowl Association (CWA), California Department of Fish and Wildlife, U.S. Fish and
Wildlife, California Department of Water Resources and Southwest Climate Science Center (U.S. Geological Survey). Field work, capture, trapping, handling and tagging of ducks was completed by: Jeffrey Kohl, Desmond Mackell, Michael Fontana, Caroline Brady, Brian Huber, Orlando Rocha, Patrick Graham, Andy Greenawalt, Brady Fettig, Andrea Mott, Clint Helms, Alex Dopkin, Melissa Hunt, Ivonne Romero, Breanne Cooney, Katharine Fielding, Katharine Cody, Nathan LaShomb, Matthew Prinzing, Daniel Essert, Jeff Taylor, Dean Podolsky, Tim Edmunds, Steve Chapelle, Bruce Wickland, Shannon Skalos, Matthew Falcon and Elliott Matchett. We thank the Grizzly Island Wildlife Area and California Department of Fish and Wildlife staff for assistance with all aspects of the field data collection. Lisa Parker provided administrative support. All activities within this manuscript have followed appropriate animal care use protocol. Use of trade, product or firm names does not imply endorsement by the U.S. Government.

\section{Funding}

Funding for this study was provided by the California Department of Water Resources and the U.S. Geological Survey and none of the funders had any input into the content of the manuscript.

\section{Availability of data and materials}

The datasets used and analyzed during the current study are available from the corresponding author on reasonable request.

\section{Authors' contributions}

$M C$ and JA conceived the original idea, design and experiment. FM authored the manuscript with editing by $M C$ and JA and input from all authors who read and approved the final manuscript. CO processed the data and analyses were conducted by CO and FM. CF contributed substantial resources and funding. SP, $\mathrm{CH}$ and $\mathrm{MH}$ contributed to experimental design and field work.

Ethics approval and consent to participate

This study was approved by the U.S. Geological Survey Western Ecological Research Center Animal Care and Use Committee. Research was conducted under Federal Banding Permit \#2114 and state SC permit \#SC-8090.

\section{Consent for publication}

Not applicable.

\section{Competing interests}

The authors declare that they have no competing interests.

\section{Publisher's Note}

Springer Nature remains neutral with regard to jurisdictional claims in published maps and institutional affiliations.

\section{Author details}

${ }^{1}$ San Jose State University Research Foundation, Moss Landing Marine Laboratories, 8272 Moss Landing Rd, Moss Landing, CA 95039, USA. ${ }^{2}$ U.S. Geological Survey, Western Ecological Research Center, Dixon Field Station, 800 Business Park Drive, Suite D, Dixon, CA 95620, USA. ${ }^{3}$ California Department of Water Resources, Suisun Marsh Program, 3500 Industrial Blvd, \#131, West Sacramento 95691, CA, USA.

Received: 21 December 2018 Accepted: 7 January 2019 Published online: 25 February 2019

\section{References}

1. Ford RG. Home range in a patchy environment: optimal foraging predictions. Am Zool. 1983;23:315-26.

2. Charnov E, Orians GH. Optimal foraging: some theoretical explorations. Seattle. 2006. http://digitalrepository.unm.edu/biol_fsp/45. Accessed 10 Oct 2017. p. 157.

3. MacArthur RH, Pianka ER. On optimal use of a patchy environment. Am Nat. 1966;100:603-9.

4. Kareiva P. Population dynamics in spatially complex environments: theory and data. Phil Trans R Soc Lond B. 1990;330:175-90.

5. Jodice PGR, Roby DD, Suryan RM, Irons DB, Kaufman AM, Turco KR, Visser GH. Variation in energy expenditure among Black-legged kittiwakes: effects of activity-specific metabolic rates and activity budgets. Physiol Biochem Zool. 2003;76:375-88. 
6. Birt-Friesen V, Montevecchi W, Cairns D, Macko S. Activity-specific metabolic rates of free-living northern gannets and other seabirds. Ecology. 1989;70: 357-67.

7. Miller ML, Ringelman KM, Schank JC, Eadie JM. SWAMP: an agent-based model for wetland and waterfowl conservation management. SIMULATION. 2014;90:52-68.

8. Saher DJ, Schmiegelow FK. Movement pathways and habitat selection by woodland caribou during spring migration. Rangifer. 2005;25:143-54.

9. Almeida-Gomes M, Vieira MV, Rocha CFD, Metzger JP, De Coster G. Patch size matters for amphibians in tropical fragmented landscapes. Biol Conserv. 2016;195:89-96

10. Schaub M, Jenni L, Bairlein F. Fuel stores, fuel accumulation, and the decision to depart from a migration stopover site. Behav Ecol. 2008;19:657-66.

11. Piersma T. Pre-migratory "fattening" usually involves more than the deposition of fat alone; 1990

12. Raveling DG. The annual cycle of body composition of Canada Geese with special reference to control of reproduction. Auk. 1979;96:234-52.

13. Guillemain M, Mondain-Monval J-Y, Weissenbacher E, Brochet A-L, Olivier A. Hunting bag and distance from nearest day-roost in Camargue ducks. Wildl Biol. 2008;14:379-85

14. Casazza ML, Coates PS, Miller MR, Overton CT, Yparraguirre DR. Hunting influences the diel patterns in habitat selection by northern pintails Anas acuta. Wildl Biol. 2012;18:1-13.

15. St. James EA, Schummer ML, Kaminski RM, Penny EJ, Burger LW. Effect of weekly hunting frequency on duck abundances in Mississippi Wildlife management areas. J Fish Wildl Manag. 2013;4:144-50.

16. Roshier DA, Doerr VA, Doerr ED. Animal movement in dynamic landscapes: interaction between behavioural strategies and resource distributions. Oecologia. 2008;156:465-77.

17. Kleyheeg E, van Dijk JG, Tsopoglou-Gkina D, Woud TY, Boonstra DK, Nolet BA, Soons MB. Movement patterns of a keystone waterbird species are highly predictable from landscape configuration. Movem Ecol. 2017;5:2.

18. Arzel C, Elmberg J, Guillemain M. Ecology of spring-migrating Anatidae: a review. J Ornithol. 2006;147:167-84.

19. Miller MR, Takekawa JY, Fleskes JP, Orthmeyer DL, Casazza ML, Haukos DA, Perry WM. Flight speeds of northern pintails during migration determined using satellite telemetry. Wilson Bull. 2005;117:364-74.

20. Yarris GS, McLandress MR, Perkins AE. Molt migration of postbreeding female mallards from Suisun marsh. California Condor. 1994;96:36-45.

21. Bengtsson D, Avril A, Gunnarsson G, Elmberg J, Söderquist P, Norevik G, Tolf C, Safi K, Fiedler W, Wikelski M. Movements, home-range size and habitat selection of mallards during autumn migration. PLoS One. 2014; 9:e100764.

22. Miller MR, Takekawa JY, Fleskes JP, Orthmeyer DL, Casazza ML, Perry WM. Spring migration of northern pintails from California's Central Valley wintering area tracked with satellite telemetry: routes, timing, and destinations. Can J Zool. 2005:83:1314-32.

23. Johnson WP, Schmidt PM, Taylor DP. Foraging flight distances of wintering ducks and geese: a review. Avian Conserv Ecol. 2014;9:2.

24. Legagneux P, Blaize C, Latraube F, Gautier J, Bretagnolle V. Variation in home-range size and movements of wintering dabbling ducks. J Ornithol. 2009;150:183-93.

25. Cox RR Jr, Afton AD. Evening flights of female northern pintails from a major roost site. Condor. 1996;98:810-9.

26. Fleskes J, Yee J, Casazza M, Miller M, Takekawa J, Orthmeyer D. Waterfowl distribution, movements, and habitat use relative to recent habitat changes in the Central Valley of California: A cooperative project to investigate impacts of the Central Valley Joint Venture and changing agricultural practices on the ecology of wintering waterfowl. Final Report: U.S. Geological Survey, Western Ecological Research Center, Dixon Field Station, Dixon, California, USA; 2005

27. Cushman SA. Animal movement data: GPS Telemetry, autocorrelation and the need for path-level analysis. In: Spat complex inform and Wildl Conserv. Japan: Springer; 2010. p. 131-49.

28. Fleming $\mathrm{CH}$, Calabrese JM, Mueller T, Olson KA, Leimgruber $\mathrm{P}$, Fagan WF. From fine-scale foraging to home ranges: a semivariance approach to identifying movement modes across spatiotemporal scales. Am Nat. 2014;183:E154-67.

29. Henry DA, Ament JM, Cumming GS. Exploring the environmental drivers of waterfowl movement in arid landscapes using first-passage time analysis. Movem Ecol. 2016;4:8.
30. Nathan R, Getz WM, Revilla E, Holyoak M, Kadmon R, Saltz D, Smouse PE. A movement ecology paradigm for unifying organismal movement research. Proc Natl Acad Sci. 2008;105:19052-9.

31. Mills KJ, Patterson BR, Murray DL. Effects of variable sampling frequencies on GPS transmitter efficiency and estimated wolf home range size and movement distance. Wild Soc Bull. 2006;34:1463-9.

32. Central Valley Joint Venture. Central Valley Joint Venture. Sacramento. California: US Fish and Wildlife Service; 2006. p. 261.

33. Fleskes JP, Yee JL. Waterfowl distribution and abundance during spring migration in southern Oregon and northeastern California. Western North American Naturalist. 2007:67:409-28.

34. Miller MR, Takekawa JY, Battaglia DS, Golightly RT, Perry WM. Spring migration and summer destinations of northern pintails from the coast of southern California. Southwest Nat. 2010;55:501-9.

35. Rienecker W. Migration and distribution of northern pintails banded in California. California Fish and Game. 1987;73:139-55.

36. Schemnitz SD, Batcheller GR, Lovallo MJ, White HB, Fall MW. Capturing and handling wild animals. In: Silvy N, editor. The wildlife techniques manual. Baltimore, MD: Johns Hopkins University Press; 2009. p. 232-69.

37. Drewien RC, Clegg KR. Capturing whooping cranes and sandhill cranes by night-lighting; 1992.

38. Haramis G, Derleth E, McAuley D. Techniques for trapping, aging, and banding wintering canvasbacks. J Field Ornithol. 1982;53:342-51.

39. Carney SM. Species, age and sex identification of ducks using wing plumage. Washington, DC: US Fish and Wildlife Service, US Department of the Interior; 1992. p. 107

40. Baldassarre GA. Ducks, Geese, and Swans of North America, vol. 1. Baltimore: Johns Hopkins University Press; 2014.

41. Kenward RE, Clarke RT, Hodder KH, Walls SS. Density and linkage estimators of home range: nearest-neighbor clustering defines multinuclear cores. Ecology. 2001;82:1905-20.

42. Phillips RA, Jose CX, Croxall JP. Effects of satellite transmitters on albatrosses and petrels. Auk. 2003;120:1082-90.

43. Fair J, Paul E and Jones J, Eds. Guidelines to the Use of Wild Birds in Research, 3rd Ed. Washington, DC: Ornithological Council; 2010.

44. Cochran WW. Willdife Telemetry. In: Schemnitz S, editor. Willdife management techniques manual. Washington, DC: The wildlife society; 1980. p. 507-20.

45. Barron DG, Brawn JD, Weatherhead PJ. Meta-analysis of transmitter effects on avian behaviour and ecology. Methods Ecol Evol. 2010;1:180-7.

46. Garrettson PR, Rohwer FC, Moser EB. Effects of backpack and implanted radiotransmitters on captive blue-winged teal. J Wildl Manag. 2000;64:216-22.

47. Pietz PJ, Krapu GL, Greenwood RJ, Lokemoen JT. Effects of harness transmitters on behavior and reproduction of wild mallards. J Wildl Manag. 1993:57:696-703.

48. Teets DA. Predicting sunrise and sunset times. Coll Math J. 2003;34:317-21.

49. R Core Team. R: a language and environment for statistical computing. Vienna, Austria: R: foundation for Statistical Computing. 2016.

50. Paulus SL. Time-activity budgets of nonbreeding Anatidae: a review, Waterfowl in winter; 1988. p. 135-52.

51. Rave DP, Cordes CL. Time-activity budget of northern pintails using nonhunted Rice fields in Southwest Louisiana. J Field Ornithol. 1993;64:211-8.

52. Birge RR. Nature of the primary photochemical events in rhodopsin and bacteriorhodopsin. Biochim Biophys Acta. 1990;1016:293-327.

53. Cashmore AR, Jarillo JA, Wu Y-J, Liu D. Cryptochromes: blue light receptors for plants and animals. Science. 1999;284:760-5.

54. Prange HD, Schmidt-Nielsen K. The metabolic cost of swimming in Ducks. J Exp Biol. 1970;53:763-77.

55. Usherwood JR, Szymanek KL, Daley MA. Compass gait mechanics account for top walking speeds in ducks and humans. J Exp Biol. 2008;211:3744-9.

56. Woakes AJ, Butler P. Swimming and diving in tufted ducks, Aythya fuligula, with particular reference to heart rate and gas exchange. J Exp Biol. 1983; 107:311-29.

57. Cooke MT. Speed of bird flight. Auk. 1933:50:309-16.

58. Hedenström A, Alerstam T. Optimal flight speed of birds. Philosophical transactions of the Royal Society of London series B. Biol Sci. 1995;348:471-87.

59. Calenge $C$. The package "adehabitat" for the R software: a tool for the analysis of space and habitat use by animals. Ecol Model. 2006:197:516-9.

60. Calenge C. Analysis of habitat selection by animals. Package 'adehabitat', version 1.8. 3. 2009. https://cran.r-project.org/web/packages/adehabitatLT. Accessed 17 Nov 2017 
61. Fleskes JP, Mauser DM, Yee JL, Blehert DS, Yarris GS. Flightless and postmolt survival and movements of female mallards molting in Klamath Basin. Waterbirds. 2010;33:208-20.

62. Pyle P. Molts and plumages of ducks (Anatinae). Waterbirds. 2005;28:208-19.

63. Fauchald $P$, Tveraa T. Using first-passage time in the analysis of arearestricted search and habitat selection. Ecology. 2003;84:282-8.

64. Beatty WS, Webb EB, Kesler DC, Naylor LW, Raedeke AH, Humburg DD, Coluccy JM, Soulliere GJ. An empirical evaluation of landscape energetic models: mallard and American black duck space use during the nonbreeding period. J Wildl Manag. 2015;79:1141-51.

65. Beatty WS, Webb EB, Kesler DC, Raedeke AH, Naylor LW, Humburg DD. Landscape effects on mallard habitat selection at multiple spatial scales during the non-breeding period. Landsc Ecol. 2014;29:989-1000.

66. Miller MR. Time budgets of northern pintails wintering in the Sacramento Valley, California. Wildfowl. 1986;36:53-64.

67. Tamisier A. Diurnal activities of green-winged teal and pintail wintering in Louisiana. Wild. 1976;27:19-32.

68. Burt JE, Barber GM, Rigby DL. Elementary statistics for geographers. New York, NY: The Guilford Press; 2009.

69. Clark PJ, Evans FC. Distance to nearest neighbor as a measure of spatial relationships in populations. Ecology. 1954;35:445-53.

70. Riitters KH, O'Neill RV, Wickham JD, Jones KB. A note on contagion indices for landscape analysis. Landsc Ecol. 1996;11:197-202.

71. ESRI. ArcGIS Desktop: Release 10. Redlands, CA: Environmental Systems Research Institute; 2011.

72. Badagián AL, Kaiser R, Peña D. Time series segmentation procedures to detect, locate and estimate change-points. In: Empirical economic and financial research: Switzerland: Springer; 2015. p. 45-59.

73. Gurarie $\mathrm{E}$, Andrews RD, Laidre KL. A novel method for identifying behavioural changes in animal movement data. Ecol Lett. 2009;12:395-408.

74. Ramsey F, Schafer D. The statistical sleuth: a course in methods of data analysis: Boston, MA: Brooks/Cole Cengage Learning; 2012.

75. Kuhn M WS, Wing J, Forester J The contrast package. 2008. https://cran.rproject.org/web/packages/contrast/. Accessed 07 Oct 2009.

76. Baddeley A, Turner R. Spatstat: an R package for analyzing spatial point patterns. J Stats Softw. 2005;12:1-42.

77. Dixon PM. Nearest neighbor methods. In: El-Shaarawi A, Piegorsch W, editors. Encyclopedia of Environmetrics. lowa, USA: lowa State University; 2002.

78. Paulus SL. Feeding ecology of gadwalls in Louisiana in winter. J Wild Manag. 1982;46:71-9.

79. Gray JM. Habitat use, movements and spring migration chronology and corridors of female gadwalls that winter along the Louisiana Gulf Coast. Baton Rouge, LA: Louisiana State University, LSU Digital Commons; 2010

80. Paulus SL. Activity budgets of nonbreeding gadwalls in Louisiana. J Wildl Manag. 1984;48:371-80.

81. Sparrow W, Newell K. Metabolic energy expenditure and the regulation of movement economy. Psychon Bull Rev. 1998:5:173-96.

82. Wooley JB Jr, Owen RB Jr. Energy costs of activity and daily energy expenditure in the Black duck. J Wildl Manag. 1978:42:739-45.

83. Nudds RL, Bryant DM. The energetic cost of short flights in birds. J Exp Biol. 2000;203:1561-72

84. Tucker VA. Energetic cost of locomotion in animals. Comp Biochem Physiol. 1970;34:841-6.

85. Tucker VA. Flight energetics in birds. Am Zool. 1971;11:115-24.

86. Schmidt-Nielsen K. Locomotion: energy cost of swimming, flying, and running. Science. 1972;177:222-8.

87. Miller MR. Newton WE. Population energetics of northern pintails wintering in the Sacramento Valley, California. J Wildl Manag. 1999;63:1222-38.

88. Carney KM. Sydeman WJ. A review of human disturbance effects on nesting colonial waterbirds. Waterbirds. 1999;22:68-79.

89. Mori Y, Sodhi NS, Kawanishi S, Yamagishi S. The effect of human disturbance and flock composition on the flight distances of waterfowl species. J Ethol. 2001;19:115-9.

90. Dooley JL, Sanders TA, Doherty PF Jr. Mallard response to experimental walk-in and shooting disturbance. J Wildl Manag. 2010;74:1815-24.

91. Boyce MS. Scale for resource selection functions. Divers Distrib. 2006;12:269-76.

92. Manly B, McDonald L, Thomas D, McDonald TL, Erickson WP. Resource selection by animals: statistical design and analysis for field studies. Netherlands: Springer Science \& Business Media; 2007. p. 233
93. Fretwell SD, Calver JS. On territorial behavior and other factors influencing habitat distribution in birds. Acta Biotheor. 1969:19:37-44.

94. Wiens JA. Habitat fragmentation: island $v$ landscape perspectives on bird conservation. Ibis. 1995:137:S97-S104.

95. Bélisle M, Desrochers A, Fortin M-J. Influence of forest cover on the movements of forest birds: a homing experiment. Ecology. 2001;82:1893-904.

96. Diffendorfer JE, Gaines MS, Holt RD. Habitat fragmentation and movements of three small mammals (Sigmodon, Microtus, and Peromyscus). Ecology. 1995;76:827-39.

97. Fleskes JP, Yee JL, Yarris GS, Loughman DL. Increased body mass of ducks wintering in California's Central Valley. J Wildl Manag. 2016;80:679-90.

98. Delnicki D, Reinecke KJ. Mid-winter food use and body weights of mallards and wood ducks in Mississippi. J Wildl Manag. 1986;50:43-51.

99. Jorde DG. Winter and spring staging ecology of mallards in south central Nebraska: MS, University of North Dakota, Grand Forks; 1981. p. 116.

100. Whyte RJ, Baldassarre GA, Bolen EG. Winter condition of mallards on the southern High Plains of Texas. J Wildl Manag. 1986;50:52-7.

101. Gaston GR, Walther D, Shaheen D, Felley JD. Winter condition of gadwalls (Anas strepera) in southwestern Louisiana. Proc La Acad Sci. 1989:52:55-61.

102. Lokemoen JT, Johnson DH, Sharp DE. Weights of wild mallard Anas platyrhynchos, gadwall a. Strepera, and blue-winged teal A. discors during the breeding season. Wild. 1990:41:122-32.

103. Owen M, Cook W. Variations in body weight, wing length and condition of mallard Anas platyrhynchos platyrhynchos and their relationship to environmental changes. J Zool. 1977;183:377-95.

104. Folk C, Hudec K, Toufar J. The weight of the mallard, Anas platyrhynchos, and its changes in the course of the year. Zool Listy. 1966;15:249-60.

105. Oring LW. Summer biology of the Gadwall at Delta, Manitoba: The Wilson Bulletin. p. 1969, 44-54.

106. Thompson JD, Baldassarre GA. Carcass composition of nonbreeding bluewinged teal and northern pintails in Yucatan, Mexico. Condor. 1990;92: 1057-65.

107. Guillemain M, Elmberg J, Gauthier-Clerc M, Massez G, Hearn R, Champagnon J, Simon G. Wintering French mallard and teal are heavier and in better body condition than 30 years ago: effects of a changing environment? Ambio J Hum Envir. 2010;39:170-80.

108. Miller MR. Northern pintail body condition during wet and dry winters in the Sacramento Valley, California. J Wildl Manage. 1986;50:189-98.

109. Weller MW. Wetland birds: habitat resources and conservation implications. Cambridge, UK: Cambridge University Press; 1999. p. 328.

110. Evans DM, Day KR. Hunting disturbance on a large shallow lake: the effectiveness of waterfowl refuges. Ibis. 2002;144:2-8.

111. Beatty WS, Kesler DC, Webb EB, Raedeke AH, Naylor LW, Humburg DD. The role of protected area wetlands in waterfowl habitat conservation: implications for protected area network design. Biol Conserv. 2014;176:144-52.

112. Owen $M$, Wells RL, Black JM. Energy budgets of wintering barnacle geese: the effects of declining food resources. Ornis Scand. 1992; 23:451-8.

113. Fryxell JM, Sinclair AR, Caughley G. Wildlife Ecology, Conservation, and management. Oxford, UK: John Wiley \& Sons; 2014. p. 500.

114. Moen AN. Wildlife ecology. San Francisco: W. H. Freeman \& Company; 1973. p. 458.
Ready to submit your research? Choose BMC and benefit from:

- fast, convenient online submission

- thorough peer review by experienced researchers in your field

- rapid publication on acceptance

- support for research data, including large and complex data types

- gold Open Access which fosters wider collaboration and increased citations

- maximum visibility for your research: over $100 \mathrm{M}$ website views per year

At $\mathrm{BMC}$, research is always in progress.

Learn more biomedcentral.com/submissions 